\section{The effect of nerve mobilization exercise in patients with rheumatoid arthritis: a pilot study}

\author{
C.-N. Lo', G. Xia ${ }^{2}$, B.P. Leung ${ }^{1}$ \\ ${ }^{1}$ Health and Social Sciences, Singapore Institute of Technology, Singapore; \\ 2Department of Rehabilitation Sciences, The Hong Kong Polytechnic University, Hong Kong
}

\begin{abstract}
SUMMARY
Rheumatoid arthritis (RA) is an autoimmune disorder characterized by chronic inflammation of the joints. The neurogenic inflammatory mechanism plays an important role in the inflammatory process of RA, and pathological changes in neural tissues in RA have also been noted. We aim to investigate treatment of the nervous system to relieve joint pain and inflammation in RA. Nerve mobilization, a nervous system-specific therapeutic exercise, was applied on RA patients to determine the effect of nerve mobilization on joint inflammation.

Twelve RA patients were recruited from the community and were randomised into an experimental and a control group. In the experimental group, the subjects were taught a set of nerve mobilization exercises while the subjects in the control group were taught a set of gentle joint mobilization exercises. Both groups were instructed to practice the exercises daily. After a 4-week period, their RA pain scale (RAPS) and pain scores were examined, as well as the C-reactive protein (CRP) and erythrocyte sedimentation rate (ESR).

Subjects in the experimental group showed improvements in RAPS and pain scores after 4 weeks of nerve mobilization exercises, while CRP and ESR values remained unaffected.

These preliminary data showed that nerve mobilization exercises might be beneficial in controlling joint pain in RA patients.
\end{abstract}

Key words: CRP; ESR; Nerve mobilisation; Neurogenic inflammation; Rheumatoid arthritis.

\section{INTRODUCTION}

heumatoid arthritis (RA) is one of the most prevalent chronic autoimmune diseases. The symptoms of RA are characterized by joint inflammation and deformities that are associated with pain and functional disability (1). The aetiology of RA remains unclear, but an increasing number of investigations have provided evidence that disease perpetuation could be due to a mixture of both immunogenic (1) and neurogenic $(2,3)$ inflammation.

The mechanism of neurogenic inflammation has been described as an inflammation that is initiated by the nervous system (4-6). The neurogenic inflammation is triggered in the tissues by the cutaneous nerves $(4,7-10)$. The evidence of neurogenic inflammation in RA is supported by a small but significant number of tyrosine hydroxylase-positive sympathetic nerve fibres, which have a negative correlation with the inflammation index, a large number of substance P-positive nerve fibres (11) and immunoreactive sensory nerve fibres with calcitonin gene-related peptide (CGRP) (12).

The current treatment algorithms for RA involve the use of both traditional and biological disease-modifying antirheumatic drugs (DMARDs) to control the disease (13). Physical treatments are also beneficial for patients to optimize physical functions, decreasing pain and improving quality of life (14-16). A paradigm is named as neurodynamic, which is a series of movements that produce physiological and mechanical events in the nervous system. They are used in physical testing to gain a response to the mechanical performance and sensitivity of the nervous sys-
Corresponding author Chi-ngai Lo

Health and Social Sciences Singapore Institute of Technology 10 Dover Drive, Singapore E-mail: lochingai@gmail.com 
tem together with the innervated tissues. The nerve mobilisation produces from $-7 \%$ to $+6 \%$ changes in length of the nerve by excursion and strain $(17,18)$. Besides the physical movements on the nerves, the mobilisation may disperse intraneural fluid, and help alleviate intraneural oedema after injury $(19,20)$. Clinically, this technique could be applied in clinical examinations and as active or passive nerve mobilization therapeutic exercises (21, 22 ). The rationale for performing nerve mobilization exercises is to remove or mobilize the pressure points on the neural tissues, reduce nerve adherence, increase neural vascularity, disperse noxious fluids and improve axoplasmic flow $(17,19,21$, $23,24)$. In addition, the mobilization of entrapped nerves could significantly normalize the excitability of sensory axons by the redistribution of sodium ion $\left(\mathrm{Na}^{+}\right)$ channels (25). This kind of nerve mobilization has been demonstrated to have both localised and systemic hypoalgesic effects $(23,24)$.

In chronic inflammatory conditions such as RA, the peripheral nerves undergo prolonged stress with mechanical compression due to swollen joints and immobilization due to a decrease in activities. As a result, ischaemia, hypoxia, endoneurial oedema, inflammation in the neural tissues and fibrin deposits occur and cause axonal degeneration, demyelination and Schwann-cell necrosis followed by remyelination $(2,3,26)$. In addition, mechanical stress has been shown to stimulate the release of substances $\mathrm{P}$ and CGRP, which cause pain in arthritic joints (27). Therefore, with the application of nerve mobilization exercises, the neural tissue might be able to restore its dynamic balance with surrounding mechanical interfaces, reduce intrinsic physical stress, improve the strain and length capacity of the nerve $(17,19,23,24,26)$. Consequently, the neurogenic inflammation and pain in RA patients could be reduced.

Therefore, we aimed to explore the effects of nerve mobilization exercises on joint inflammation and pain in patients with RA.

\section{Procedure}

All patients fulfilled the American College of Rheumatology 1987 revised RA criteria (28). Other inclusion criteria were being an adult ( $>18$ years of age) of either gender, and chronicity of the disease greater than one year. The exclusion criteria were severe joint pain affecting global mobility, currently receiving physiotherapy for RA, recent joint injections and a change in corticosteroids or other disease-modifying anti-rheumatic drugs in the 3 months prior to the study (29). Subjects were also excluded if they had poor balance or significant pain that prevented them from performing the nerve mobilization exercises. RA patients were recruited in accordance with the guidelines of the Human Subjects Ethics Sub-committee of the University Research Committee, The Hong Kong Polytechnic University. Ethical approval was granted by the committee with written informed consent collected from all subjects before data collection. Subjects were then ran-

Table I - Actions for nerve mobilizations.

\begin{tabular}{|l|l|}
\hline \multicolumn{1}{|c|}{ Actions } \\
\hline Median nerve (Figure 1) & $\begin{array}{l}\text { Sit on a plinth, supported by elbows, with wrists and fingers extended and arms by the sides. Shift the } \\
\text { body weight to the left and right sides to give a pulling sensation along the palm side of the arm on } \\
\text { the same side. }\end{array}$ \\
\hline Musculocutaneous nerve (Figure 2) & $\begin{array}{l}\text { Clench a fist, bend the fist down, straighten the elbow and extend the shoulder as though marching. } \\
\text { Perform the actions with left and right arm oppositely and simultaneously. }\end{array}$ \\
\hline Saphenous nerve (Figure 3) & $\begin{array}{l}\text { Stand with feet apart, stretching the leg out behind; place the ankle of the stretched leg in dorsiflexion } \\
\text { and eversion with the use of a towel role. The saphenous nerve is mobilised when the front of the knee } \\
\text { is bent and driven forwards. }\end{array}$ \\
\hline $\begin{array}{l}\text { Entire nervous system (Figure 4) } \\
\text { (Neural tissues on the back of the } \\
\text { lower limb together with the meninges) }\end{array}$ & $\begin{array}{l}\text { In a sitting position, slump the body, bend the head down and place the arms behind the body. The } \\
\text { stretched leg is actively kicked up with ankle dorsiflexion until a stretching sensation occurs in the } \\
\text { posterior thigh and calf. }\end{array}$ \\
\hline
\end{tabular}




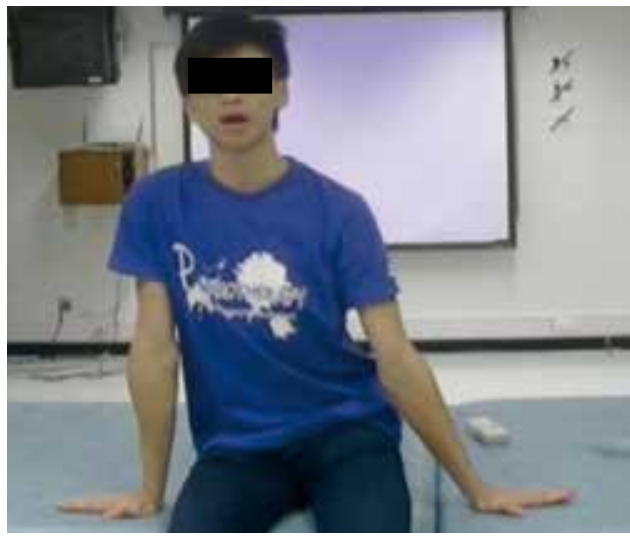

Figure 1 - Median nerve mobilization.

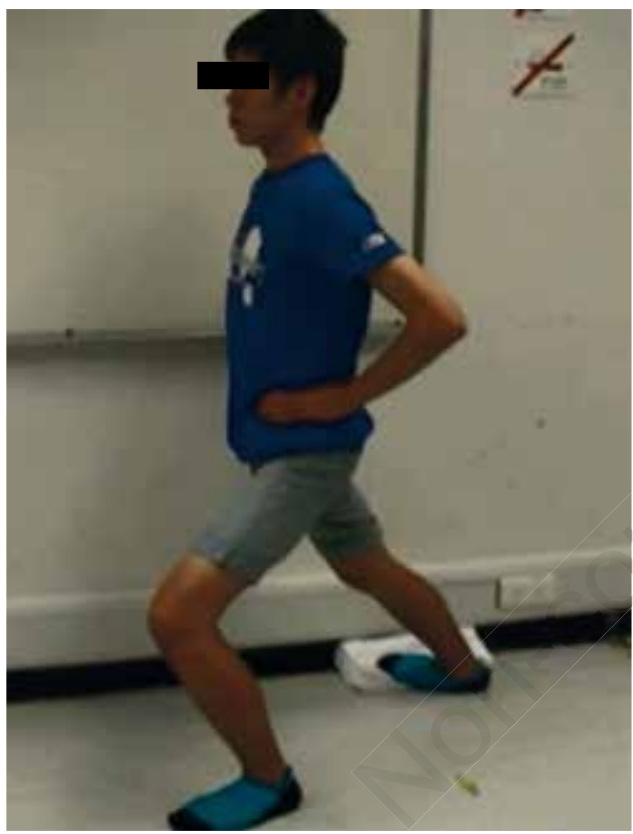

Figure 3 - Saphenous nerve mobilization.

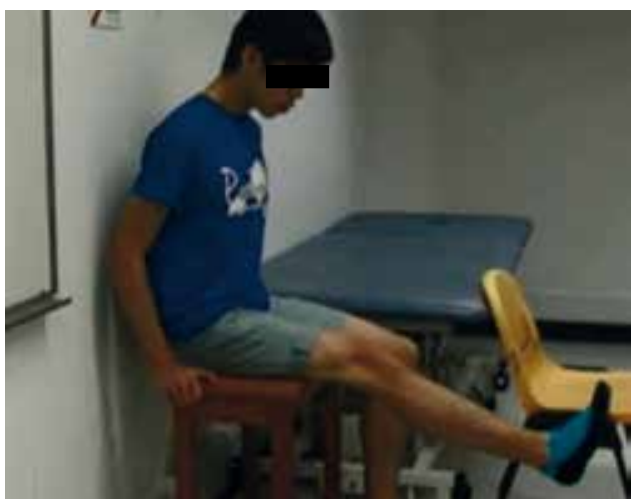

Figure 4 - Mobilization of the entire nervous system.

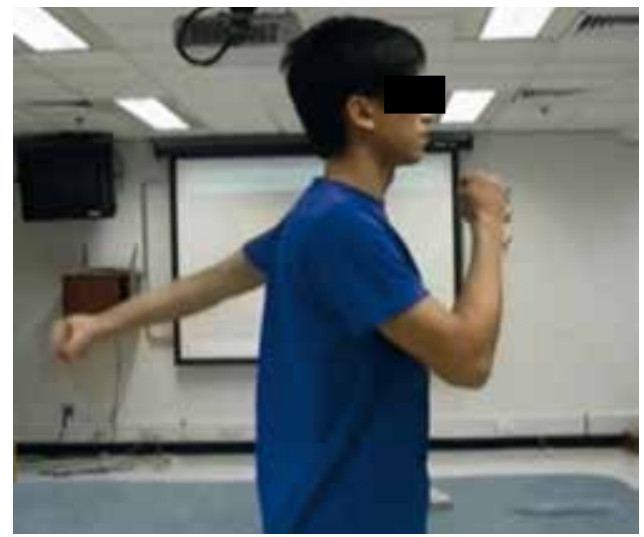

Figure 2 - Musculocutaneous nerve mobilization.

domized, according to their age ranges, into the control group or the experimental group, with similar clinical demographics.

\section{Interventions}

Subjects in the experimental group were taught a set of active nerve mobilization exercises, the two types of which are classified as slider and tensioner applications. The former implies less challenge and allows the nervous system a large degree of neural movement; the tensioner places a load on both ends of the nervous system and is a more aggressive technique. In this study, the tensioner technique was applied because patients with RA usually had no active neurogenic symptoms and the technique produces a larger excursion on the nerve $(17,22)$.

The series of nerve mobilization exercises comprised four actions (Table I; Figures 1-4) that focus to a greater extent on the major innervating cutaneous nerves: the median nerve, musculocutaneous nerve, saphenous nerve and the entire nervous system $(21,23,30,31)$. Each action of the mobilization exercises was repeated 10 times but was not continued when subjects experienced the stretching sensation and then returned to the starting position. The subjects were instructed to perform the series of exercises daily, twice a day (23).

In the control group, subjects were given a set of joint mobilization exercises that comprised five actions to mobilize the fingers, wrists, elbows and shoulders, the spine and 
the entire lower limbs. The movements were gentle, not touching the end range of the joints. The subjects were instructed to repeat the actions 10 times; the whole series of actions took about 5 minutes or less. The mobilization exercises were not supposed to impose any stress on the joints, muscles or the cardiopulmonary system.

An exercise log book was provided for each subject to record compliance with the exercises. Recorded exercise DVDs were also given to the subjects for them to follow and practice daily.

Patients' anti-rheumatic therapies were recorded throughout the study period. Subjects were instructed to suspend the exercises and contact the investigator if symptoms flared up during the period.

\section{Pain assessment tools and inflammatory biomarkers}

The Rheumatoid Arthritis Pain Scale (RAPS) was used to rate the severity of pain, before and after the study period. The questionnaire comprised 24 items with a scale from 0 to 6 to quantify the severity of pain and inflammation $(32,33)$, where 0 represents a condition that always occurs, and 6 represents a condition that never occurs. For items 1-24, the lowest total score was 0 and the highest score was 144 (Appendix 1). This questionnaire was chosen because the questions concern both pain, which is the greatest concern of patients with RA (34), and joint inflammation. Cronbach's alpha for the total RAPS was found to be 0.91 while the subscale alpha coefficients were between 0.64 and 0.86 .
The visual analogue scale-numeric rating scale (VAS-NRS) is listed in RAPS as the last item and is a subjective pain measurement rated from 0 to 10 to describe the level of pain: 0 represents none, and 10 represents severe. The RAPS correlations with VAS-NRS and that with total joint count were 0.67 and 0.52 , respectively (33). The total joint score in RAPS was not recorded as a rheumatologist was not available on the site. Inflammatory biomarkers C-reactive protein (CRP) and erythrocyte sedimentation rate (ESR) were tested in either the university clinic or in the public hospitals where the subjects were being followed up (35-37).

\section{Statistics}

Results were analysed using IBM SPSS 23. The nonparametric Mann-Whitney $U$ test was applied to analyze differences between the groups and the Wilcoxon test was used for within-group comparisons.

\section{RESULTS}

A total of 12 RA patients were recruited into the study, with two subjects in the experimental group subsequently dropped out: one lost contact during follow-up, and one developed an infection after the first screening. One subject was excluded from the control group due to disease flare. No statistical difference in demographics and baseline measurements was found between the two groups (Table II).

After 4 weeks, the subjects in both groups demonstrated good compliance with the

Table II - Characteristics of patients with rheumatoid arthritis.

\begin{tabular}{|l|c|c|}
\hline Characteristics & Control group $(\mathbf{n}=4)$ & Experimental group $(\mathbf{n}=5)$ \\
\hline Age (years, mean \pm S.D.) & $52-67(59.8 \pm 6.3)$ & $39-68(55.2 \pm 11.4)$ \\
\hline Male:Female & $1: 3$ & $0: 5$ \\
\hline Disease duration (years, mean \pm S.D.) & $2-6(4.1 \pm 1.7)$ & $2-15(5.7 \pm 5.8)$ \\
\hline Therapy & 2 & 3 \\
\hline Methotrexate & 2 & 2 \\
\hline Sulfasalazine & 1 & 1 \\
\hline Leflunomide & 2 & 2 \\
\hline Corticosteroids (Prednisolone) & 1 & 1 \\
\hline Non-steroidal anti-inflammatory drugs (NSAID) & & \\
\hline
\end{tabular}


exercises according to the exercise log. The changes in values of RAPS and pain level, CRP and ESR were compared between the 2 groups, before and after intervention (Tables III and IV). The experimental group reported a better maintenance or improvement of the RAPS and pain level scores (Table III). However, it should be noted that the inconsistency in values at baseline might induce a favourable or unfavourable bias to the groups. Both groups presented fluctuation in CRP and ESR values, but no particular trend could be observed. Overall, the outcomes of the two groups after the study period showed no statistical difference.

\section{DISCUSSION}

Our preliminary data demonstrate the positive effect of nerve mobilization exercises on subjective pain scores in RA patients while ESR and CRP remains unmodified. The use of nerve mobilization on patients with RA was based on the idea that RA involves neurogenic inflammation which can be influenced by mechanical stimulation of immune-reactive sensory nerve fibres $(11,12,35)$. Cutaneous nerves are physically inelastic and mechanically sensitive followed by inflammation (26, 36, 37), chronic arthritis such as RA implies mechanical stress which induces degenerative changes in the nerves $(2,3)$ and possibly exaggerates the release of inflammatory neuropeptides $(11,12,35)$. Experimental studies discovered more physiological
Table III - Comparison of RAPS and VAS-NRS scores, increase in RAPS values is a favourable sign which represents less frequent pain.

\begin{tabular}{|l|c|c|c|c|}
\hline Control group & Pre RAPS & Post RAPS & Pre VAS & Post VAS \\
\hline Subject 1 & 133 & $123 \downarrow$ & 1 & $3 \uparrow$ \\
\hline Subject 2 & 105 & $98 \downarrow$ & 2 & $2-$ \\
\hline Subject 3 & 113 & $84 \downarrow$ & 3 & $3-$ \\
\hline Subject 4 & 85 & $82 \downarrow$ & 6 & $4 \downarrow$ \\
\hline
\end{tabular}

\section{Experimental group}

\begin{tabular}{|l|c|c|c|c|}
\hline Subject 5 & 94 & $95 \uparrow$ & 4 & $4-$ \\
\hline Subject 6 & 82 & $124 \uparrow$ & 5 & $2 \downarrow$ \\
\hline Subject 7 & 90 & $102 \uparrow$ & 4 & $3 \downarrow$ \\
\hline Subject 8 & 87 & $99 \uparrow$ & 5 & $5-$ \\
\hline Subject 9 & 116 & $131 \uparrow$ & 3 & $2 \downarrow$ \\
\hline
\end{tabular}

Remarks: $\uparrow$ Improvement, $\downarrow$ Deterioration, - no change.

mechanisms of the nerve mobilization. The mobilization was shown to redistribute the sodium ion channels of sensory axons (25), increase neural growth factor and myelin protein zero in injured nerves $(38,39)$. Overall, the therapeutic effects of the nerve mobilization could be accounted for by reduction of physical stress through the movements of the nerves $(17,18)$ and intraneural fluid dispersion $(19,20)$, normalization of sensory axons excitability (25), and promotion of nerve regeneration by stimulating expression of neural growth factor and myelin protein zero $(38,39)$.

As a pilot study, the methodology had several limitations such as sample size, subjects' homogeneity and the length of the follow-up period. Due to the limited sample size, although randomization was conducted and the baseline CRP and ESR

Table IV - Comparison of CRP and ESR values.

\begin{tabular}{|l|c|c|c|c|}
\hline Control group & Pre ESR (mm/hr) & Post ESR (mm/hr) & Pre CRP (mm/L) & Post CRP (mm/L) \\
\hline Subject 1 & 10 & 16 & 1.3 & 1 \\
\hline Subject 2 & 34 & 45 & 4.5 & 17.4 \\
\hline Subject 3 & 22 & 29 & 5 & 1 \\
\hline Subject 4 & 10 & 4 & 3.3 & 1 \\
\hline Experimental group & 23 & 19 & 4.8 & 4.5 \\
\hline Subject 5 & 4 & 3 & 1 & 1 \\
\hline Subject 6 & 10 & 12 & 6.5 & 6.5 \\
\hline Subject 7 & 38 & 15 & 13.9 & 1 \\
\hline Subject 8 & 30 & 35 & 3.3 & 0.43 \\
\hline Subject 9 & \multicolumn{5}{|l|}{} \\
\hline
\end{tabular}


were similar in two groups, a minor and statistical insignificant $(\mathrm{p}>0.05)$ inequality in RAPS and VAS-NRS was noted. When compared to the control group, the experimental nerve mobilization appeared to be positive after the intervention. Disease activity score such as 28 joints (DAS28) is

\section{APPENDIX 1}

\section{Rheumatoid Arthritis Pain Scale (RAPS)}

DIRECTIONS: The following items relate to pain and arthritis. For each item, choose one number from 0 (never) to 6 (always) to describe how you have felt in the last week.

$\begin{array}{ccccccc}\begin{array}{c}0 \\ \text { Always }\end{array} & 1 & 2 & 3 & 4 & 5 & \begin{array}{c}6 \\ \text { Never }\end{array}\end{array}$

1. I would describe my pain as gnawing.

2. I would describe my pain as aching.

3. I would use the word exhausting to describe my pain.

4. I would describe my pain as annoying.

5. I am in constant pain.

6. I would describe my pain as rhythmic.

7. I have swelling of at least one joint.

8. I have morning stiffness of one hour or more.

9. I have pain on motion of at least one joint.

10. I cannot perform all the everyday tasks I normally would because of pain.

11. Pain interferes with my sleep.

12. I cannot decrease my pain by using methods other than taking extra medication.

13. I would describe my pain as burning.

14. I find that I guard my joints to reduce pain.

15. I brace myself because of the pain.

16. My pain is throbbing in nature.

17. I would describe my pain as sharp.

18. I would say my pain is severe.

19. I feel stiffness in my joints after rest.

20. My joints feel hot.

21. I feel anxious because of pain.

22. I would describe my pain as tingling.

23. I feel my pain is uncontrollable.

24. I feel helpless to control my pain.

When looking at the scale below, overall I would rate my pain as.

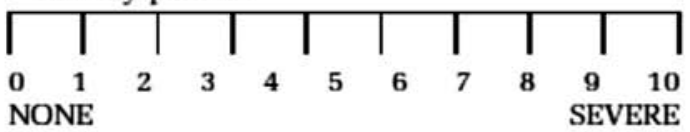

Your doctor will complete your score based on his/her examination of your joints.

Total joint score:

Anderson DL. Development of an instrument to measure pain in rheumatoid arthritis: Rheumatoid Arthritis Pain Scale (RAPS). Arthritis Rheum. 2001;45(4):317-23. a standard clinical tool in evaluating RA disease activity, and may serve as a reference in RA medication adjustment (40). Although CRP, ESR and subjects' response were available, the study was not conducted in a hospital setting with the support of either a rheumatologist or a specialized trained nurse, thus reliable swollen joint counts were not available (41).

\section{CONCLUSIONS}

Early pharmaceutical treatments have been the major intervention for RA, such as biological and new non-biological DMARD. Patients benefit from better control of the disease and prevention of early joint damage (13). Our preliminary data has demonstrated the use of nerve mobilization exercise in patients with RA to as additional modalities in managing pain and inflammation, and merit further investigation.

Acknowledgments: the authors would like to offer special thanks to the University Health Clinic for the assistance in performing ESR and CRP in this study.

Conflict of interest: the authors declare no conflict of interest.

\section{REFERENCES}

1. Firestein GS, McInnes IB. Immunopathogenesis of rheumatoid arthritis. Immunity. 2017; 46: 183-96.

2. Agarwal V, Singh R, Wiclaf, et al. A clinical, electrophysiological, and pathological study of neuropathy in rheumatoid arthritis. Clin Rheumatol. 2008; 27: 841-4.

3. Rempel D, Dahlin L, Lundborg G. Pathophysiology of nerve compression syndromes: response of peripheral nerves to loading. J Bone Joint Surg Am. 1999; 81: 1600-10.

4. Steinhoff M, Ständer S, Seeliger S, et al. Modern aspects of cutaneous neurogenic inflammation. Arch Dermatol. 2003; 139: 1479-88.

5. Schmelz M, Petersen LJ. Neurogenic inflammation in human and rodent skin. News Physiol Sci. 2001; 16: 33-7.

6. Geppetti P, Nassini R, Materazzi S, Benemei $\mathrm{S}$. The concept of neurogenic inflammation. BJU Int. 2008; 101: 2-6.

7. Chiu IM, von Hehn C a, Woolf CJ. Neurogenic inflammation and the peripheral nervous 
system in host defense and immunopathology. Nat Neurosci. 2012; 15: 1063-7.

8. Kidd BL, Mapp PI, Blake DR, et al. Neurogenic influences in arthritis. Ann Rheum Dis. 1990; 49: 649-52.

9. Levine JD, Khasar SG, Green PG. Neurogenic inflammation and arthritis. Ann N Y Acad Sci. 2006; 1069: 155-67.

10. Grässel SG. The role of peripheral nerve fibers and their neurotransmitters in cartilage and bone physiology and pathophysiology. Arthritis Res Ther. 2014; 16: 485.

11. Miller LE, Jüsten HP, Schölmerich J, Straub RH. The loss of sympathetic nerve fibers in the synovial tissue of patients with rheumatoid arthritis is accompanied by increased norepinephrine release from synovial macrophages. FASEB J. 2000; 14: 2097-107.

12. Wang H, Zhang X, He J-Y, et al. Increasing expression of substance $P$ and calcitonin generelated peptide in synovial tissue and fluid contribute to the progress of arthritis in developmental dysplasia of the hip. Arthritis Res Ther. 2015; 17: 4.

13. Smolen JS, Aletaha D, McInnes IB. Rheumatoid arthritis. Lancet (London, England). 2016; 6736: 1-16.

14. Baillet A, Payraud E, Niderprim V-A, et al. A dynamic exercise programme to improve patients' disability in rheumatoid arthritis: a prospective randomized controlled trial. Rheumatology (Oxford). 2009; 48: 410-5.

15. Christie A, Jamtvedt G, Dahm KT, et al. Effectiveness of nonpharmacological and nonsurgical interventions for patients with rheumatoid arthritis: an overview of systematic reviews. Phys Ther. 2007; 87: 1697-715.

16. Sjöquist ES, Almqvist L, Asenlöf $P$, et al. Physical-activity coaching and health status in rheumatoid arthritis: a person-oriented approach. Disabil Rehabil. 2010; 32: 816-25.

17. Coppieters MW, Butler DS. Do "sliders" slide and "tensioners" tension? An analysis of neurodynamic techniques and considerations regarding their application. Man Ther. 2008; 13: 213-21.

18. Silva A, Manso A, Andrade R, et al. Quantitative in vivo longitudinal nerve excursion and strain in response to joint movement: a systematic literature review. Clin Biomechan. 2014; 29: 839-47.

19. Brown CL, Gilbert KK, Brismee J-M, et al. The effects of neurodynamic mobilization on fluid dispersion within the tibial nerve at the ankle: an unembalmed cadaveric study. J Man Manip Ther. 2011; 19: 26-34.

20. Gilbert KK, Smith MP, Sobczak S, et al. Effects of lower limb neurodynamic mobilization on intraneural fluid dispersion of the fourth lumbar nerve root: an unembalmed cadaveric investigation. J Man Manip Ther. 2015; 23: 239-45.
21. Butler DS, Matheson J, Boyaci A. The sensitive nervous system. 1st ed. Unley: Noigroup Publications; 2000. pp 96-127, 256-273, 342367.

22. Shacklock M. Clinical neurodynamics: a new system of musculoskeletal treatment. Edinburgh - New York: Elsevier ButterworthHeinemann; 2005. pp 153-158.

23. Ellis RFHW. Neural mobilization: A systematic review of randomized controlled trials with an analysis of therapeutic efficacy. J Man Manip Ther. 2008; 16: 8-22.

24. Beneciuk JM, Bishop MD, George SZ. Effects of upper extremity neural mobilization on thermal pain sensitivity: a sham-controlled study in asymptomatic participants. J Orthop Sports Phys Ther. 2009; 39: 428-38.

25. Ginanneschi F, Cioncoloni D, Bigliazzi J, et al. Sensory axons excitability changes in carpal tunnel syndrome after neural mobilization. Neurol Sci. 2015; 36: 1611-5.

26. Topp KS, Boyd BS. Structure and biomechanics of peripheral nerves: nerve responses to physical stresses and implications for physical therapist practice. Phys Ther. 2006; 86: 92109.

27. Grässel S, Muschter D. Peripheral nerve fibers and their neurotransmitters in osteoarthritis pathology. Int J Mol Sci. 2017; 18: 931.

28. Arnett FC, Edworthy SM, Bloch DA, et al. The american rheumatism association 1987 revised criteria for the classification of rheumatoid arthritis. Arthritis Rheum. 1988; 31: 315-24.

29. Meireles SM, Jones A, Jennings F, et al. Assessment of the effectiveness of low-level laser therapy on the hands of patients with rheumatoid arthritis: a randomized double-blind controlled trial. Clin Rheumatol. 2010; 29: 501-9.

30. Butler David S. The neurodynamic techniques: a definitive guide from the Noigroup team. 1st ed. Adelaide City: Noigroup Publications; 2005. pp 1-8, 29-32, 33-48, 69-72, 73-93.

31. Morganti CM, McFarland EG, Cosgarea AJ. Saphenous neuritis: a poorly understood cause of medial knee pain. J Am Acad Orthop Surg. 2002; 10: 130-7.

32. Anderson DL. Development of an instrument to measure pain in rheumatoid arthritis: Rheumatoid Arthritis Pain Scale (RAPS). Arthritis Rheum. 2001; 45: 317-23.

33. Burckhardt CS, Jones KD. Adult measures of pain: The McGill Pain Questionnaire (MPQ), Rheumatoid Arthritis Pain Scale (RAPS), Short-Form McGill Pain Questionnaire (SFMPQ), Verbal Descriptive Scale (VDS), Visual Analog Scale (VAS), and West HavenYale Multidisciplinary Pain Inven. Arthritis Rheum. 2003; 49: S96-104.

34. Heiberg T, Kvien TK. Preferences for im- 
proved health examined in 1,024 patients with rheumatoid arthritis: pain has highest priority. Arthritis Rheum. 2002; 47: 391-7.

35. Pongratz G, Straub RH. Role of peripheral nerve fibres in acute and chronic inflammation in arthritis. Nat Rev Rheumatol. 2012; 9: 117-26.

36. Greening J, Dilley A, Lynn B. In vivo study of nerve movement and mechanosensitivity of the median nerve in whiplash and nonspecific arm pain patients. Pain. 2005; 115 : 248-53.

37. Dilley A, Lynn B, See JP. Pressure and stretch mechanosensitivity of peripheral nerve fibres following local inflammation of the nerve trunk. Pain. 2005; 117: 462-72.

38. da Silva JT, Santos FM dos, Giardini AC, et al. Neural mobilization promotes nerve regeneration by nerve growth factor and myelin pro- tein zero increased after sciatic nerve injury. Growth Factors. 2015; 33: 8-13.

39. Santos FM, Silva JT, Giardini AC, et al. Neural mobilization reverses behavioral and cellular changes that characterize neuropathic pain in rats. Mol Pain. 2012; 8: 1744-8069-8-57.

40. Fransen J, Stucki G, van Riel PLCM. Rheumatoid arthritis measures: Disease Activity Score (DAS), Disease Activity Score-28 (DAS28), Rapid Assessment of Disease Activity in Rheumatology (RADAR), and Rheumatoid Arthritis Disease Activity Index (RADAI). Arthritis Rheum. 2003; 49: S214-24.

41. Cheung PP, Ruyssen-Witrand A, Gossec L, et al. Reliability of patient self-evaluation of swollen and tender joints in rheumatoid arthritis: a comparison study with ultrasonography, physician, and nurse assessments. Arthritis Care Res (Hoboken). 2010; 62: 1112-9. 